\title{
Helping certain patients end their lives
}

\section{Assisted Death: A Study in Ethics \& Law L.W. Sumner}

Oxford University Press; 2011.

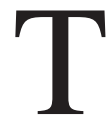
he Hippocratic oath clearly states: "I will not give a lethal drug to anyone if I am asked, nor will I advise such a plan." And yet, this happens all the time. According to the Attorney General of the High Council of the Netherlands, while $1.8 \%$ and $0.3 \%$ of all deaths in that country in 1990 were the result of euthanasia and assisted suicide, $17.5 \%$ of deaths were directly attributable to "alleviation of pain." Similarly, a study in Australia found almost $31 \%$ of all deaths in that country in 1997 were hastened by opioids given to relieve pain.

Yes, one could argue, but the doctors who gave the terminal sedation did not intend for their patients to die; that was simply a (predictable) consequence of their attempts at pain control. Surely there must be some ethical distinction between administering an injection with the express intention of causing a patient's death and doing so in order to relieve pain and suffering, even if that

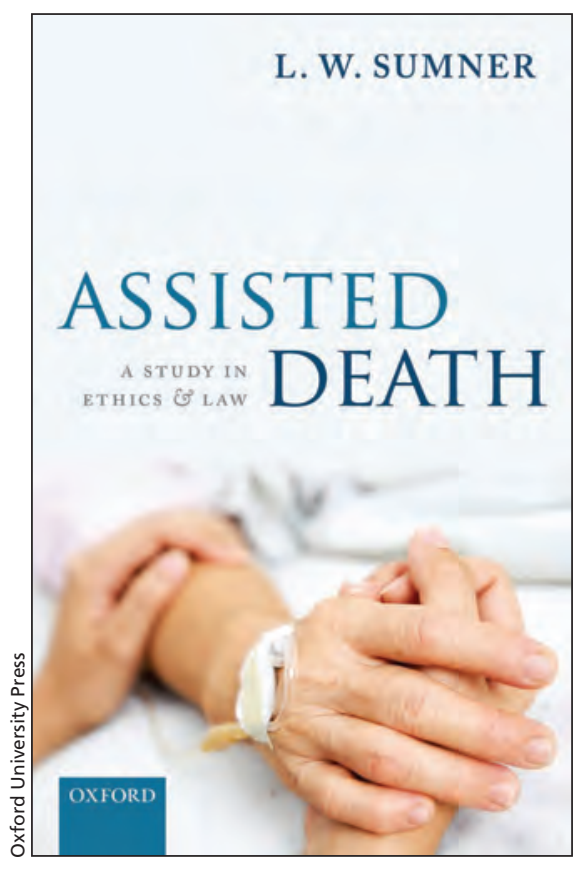

decide to drown their nephews during their nightly baths. Smith sneaks into the bathroom, drowns his nephew, and makes it look like an accident. Jones enters his nephew's bathroom as well, but just as he does, the boy slips, strikes his head, and sinks under the water; Jones stands by and does nothing until he is certain that the child is dead. Each

\section{This provocative book forces readers to confront their biases, fears and their own mortality.}

also leads to respiratory suppression and death?

Perhaps, says L.W. Sumner, professor emeritus of Law and Philosophy at the University of Toronto, but it is not consequential enough to really matter. He explains this through the stories of two men, Smith and Jones, who stand to inherit great fortunes should their six-year-old nephews die, and who both is guilty of his nephew's death, one by active commission, the other by passively allowing it to happen. Marshaling this and other arguments, Sumner concludes that "when all relevant factors are equal, assisted death is not worse than either withholding/withdrawing treatment or the administration of opioids or sedative at dose levels that may hasten death."
Sumner believes that physicians do have a role to fill in helping certain patients end their lives, either through assisted suicide or voluntary euthanasia, provided certain conditions are met. These include the patient voluntarily requesting the physician to do so; being competent to make the request; understanding the diagnosis and all of the available treatment options for it; and being in a state of "intolerable suffering" which cannot be relieved except by measures which will also have the effect of hastening death.

Countering the argument that the human "right to life" is inalienable, Sumner argues not only that it can, but that it should indeed be waived under certain circumstances. "Denying the power of waiver seems inconsistent with the very function of rights," he states, explaining that the theories about the function of rights govern the protection of choices and interests. Preventing a person suffering through the final stages of a terminal illness from choosing to end their agony and their life fulfills neither of these. Answering those who find virtue in suffering by claiming that it builds character, he writes: "while there may be some measure of truth to these claims $[\ldots]$ it would be cruel to bring them into play for patients who are suffering through the dying process. For them, there will be no future goods to compensate for the present evil."

Sumner points out that while assisted suicide and euthanasia generate a lot of controversy, terminal sedation, the cause of many more deaths, remains wholly unregulated despite it being just as prone to "slippery slopes, mistakes and abuses" as the others. Sumner proposes legalizing physicianassisted death, and points to growing support for this among the general public as well as by physician groups such as the Quebec College of Physicians. 
The fact that Sumner is a philosopher, and not a physician (or professional politician) makes his perspective refreshing and very welcome. Ultimately, the conversations about end-of-life, assisted suicide, terminal sedation as well as those about allocation of increasingly scarce resources to the terminally ill will need to be held between representatives of different sectors of society. These include philosophers, ethicists, scientists, physicians, clergy, jurists and lay people, among others. Although Sumner does not link the two, the firestorm which erupted in the United States about "death panels" surrounding the proposal to fund end-of-life planning through Medicare as part of the Patient Protection and Affordable Care Act demonstrates how easily they can be. In order for society to reach consensus about end-of-life care it is important for citizens to feel their voices are being heard, and this will only happen if the discussion is broadened to include multiple outlooks.

In Assisted Death, Sumner meets the three rules he sets out for himself in the introduction to the book: being fair to one's opponents; to the readers; and to the facts. The book is very well written, and certain to spark a lively debate. It is especially well-timed given the growing attention to end-of-life care here in North America in the last several years. Provocative in the best sense possible, it forces readers to confront their biases, fears and their own mortality and what they themselves might choose to do in circumstances similar to those discussed in the book.

\section{Dennis Rosen MD}

Assistant in Medicine

Children's Hospital Boston

Boston, Mass.

CMAJ 2012. DOI:10.1503/cmaj.120089 